\title{
Cinco mulheres: vozes em ricochete
} Ivete Lara Camargos Walty ${ }^{1}$

Sertânia é a terra natal de Marcelino Freire. Lá morava sua mãe, que expressava sua raiva batendo panelas. O barulho acordou o homem no menino que espreguiçava sob o coro de ruídos. Ouvidos abertos, ele passa a escutar e a fazer ecoarem outras vozes indignadas que atravessam tempos e espaços, cidade e campo, ruas e lixões. As narradoras de "Muribeca", "Darluz", "Da Paz", "Comadre" e "Totonha" são faces de mulheres a exibir e/ou forçar as cercas que as confinam. Seu grito contra uma sociedade excludente e hipócrita atravessa os textos deslocando paradigmas e valores.

Em "Muribeca", o lixo metaforiza a ordem social que valoriza a mercadoria em detrimento do ser humano, quando, ironicamente, a narradora reclama da remoção do lixão, espaço de sobrevivência de um segmento dessa mesma sociedade.

Em "Darluz", cujo título condensa aquela que seria a principal função feminina, em um monólogo representado, uma mãe confessa que, mal nascem seus filhos, ela os entrega para outras pessoas. Mais uma vez os valores sociais são dessacralizados, quando exibidos por ângulos outros que os comumente apresentados.

A brancura da paz se mancha de sangue na voz de Da Paz, que se interroga e ao leitor sobre o processo de violência que abala a sociedade, sem, no entanto, confiná-lo a espaços predeterminados. Antes, a voz da mãe que perdeu o filho e não tem quem o defenda põe o dedo na ferida social, gritando não apenas pela sua dor, mas pela dor de uma sociedade que não assume sua responsabilidade no jogo injusto que é jogado nos bastidores de ruas e praças.

Totonha desfia seu rosário de queixas/reclamações: "Tem esforço mais esforço que o meu esforço?" (Freire, 2007, p. 20)2. Nessa latomia, a narradora fala do lugar da sabedoria popular, confrontando-a ao saber instituído aí representado pela professora que vem alfabetizar adultos, cumprindo metas administrativas do governo.

\footnotetext{
${ }^{1}$ Doutora em Literatura Comparada e Teoria Literária. Professora do Programa de Pós-graduação em Letras da Pontifícia Universidade Católica de Minas Gerais (PUC-Minas), Belo Horizonte, Minas Gerais, Brasil. Professora aposentada da Faculdade de Letras da Universidade Federal de Minas Gerais (UFMG), é pesquisadora nível 1 D do CNPq. E-mail: iwalty2@yahoo.com.br

${ }^{2}$ Todas as citações referem-se a essa edição. Observe-se, no entanto, que os contos foram publicados também em outros livros do autor.
} 
No conto "Comadre", tem-se lado a lado a fala do afilhado rebelde e a da madrinha, que, por sua vez, reproduz valores do senso-comum. As duas falas se intercruzam, instalando no texto um contraponto desvelador que dá ao pobre o direito de ter desejos e não apenas necessidades. A voz do menino revoltado questiona instituições como a família e a igreja em sua tentativa de moldar o caminho das pessoas, sobretudo dos desvalidos.

O texto de Marcelino é uma condensação de gritos, uma latomia, que incomoda o leitor (fazendo-o acordar?).

\section{Muribeca: do lixo}

O primeiro elemento a saltar aos olhos do leitor na leitura do texto em pauta é a quantidade de interrogações que o permeiam:

É a vida da gente o lixão. E por que é que agora querem tirar ele da gente? O que é que eu vou dizer pras crianças? Que não tem mais brinquedo? Que acabou o calçado? Que não tem mais história, livro, desenho?

E o meu marido, o que vai fazer? Nada? Como ele vai viver sem as garrafas, sem as latas, sem as caixas? Vai perambular pela rua, roubar pra comer?

E o que eu vou cozinhar agora? Onde vou procurar tomate, alho, cebola? Com que dinheiro vou fazer sopa, vou fazer caldo, vou inventar farofa? (Freire, 2007, p. 9).

Tais interrogações imprimem no texto a figura de um interlocutor que mobiliza as dúvidas lançadas pela personagem quando questiona a mudança ou fechamento do lixão, fonte de sobrevivência de sua família. Essas dúvidas, porém, não são partilhadas com o interlocutor como pedido de ajuda ou solidariedade; o que se nota desde o início é um tom de indignação, como acontece em outros contos do autor. Essa indignação ratifica-se pelo uso do imperativo que acompanha as frases interrogativas: Fale, fale. Explique: o que é que a gente vai fazer da vida? O que a gente vai fazer da vida? Não pense que é fácil. Nem remédio pra dor de cabeça eu tenho. Como vou me curar quando me der uma dor no estômago, uma coceira, uma caganeira? Vá, me fale, me diga, me aconselhe. Onde vou encontrar tanto remédio bom? E esparadrapo e band-aid e seringa? (Freire, 2007, p. 10, grifo nosso).

Esse moço a que se dirige a narradora pode ser visto como a metonímia daquele que escreveu a história a partir do lugar de escuta. Na medida em 
que se desdobra o discurso, no entanto, caracterizando os lugares da narradora e do narratário, o círculo enunciativo se alarga, acolhendo, além do leitor, vários interlocutores - políticos, empresários - a quem se atribui responsabilidade pelo estado de coisas em que se encontra a narradora

O povo do governo devia pensar três vezes antes de fazer isso com chefe de família. Vai ver que eles estão de olho nessa merda aqui. Nesse terreno. Vai ver que eles perderam alguma coisa. É. Se perderam, a gente acha. A gente cata. A gente encontra. Até bilhete de loteria, lembro, teve gente que achou. Vai ver que é isso, coisa da Caixa Econômica. Vai ver que é isso, descobriram que lixo dá lucro, que pode dar sorte, que é luxo, que lixo tem valor (Freire, 2007, p. 10-11).

Explicitam-se as relações de poder que sustentam o status quo.

Por exemplo, onde a gente vai morar, é? Onde a gente vai morar? Aqueles barracos, tudo ali em volta do lixão, quem é que vai levantar? Você, o governador? Não. Esse negócio de prometer casa que a gente não pode pagar é balela, é conversa pra boi morto. Eles jogam a gente é num esgoto. Pr'onde vão os coitados desses urubus? A cachorra, o cachorro? (Freire, 2007, p. 11).

Em um mecanismo de desvelamento do lugar ocupado por essa narradora e o grupo social que ela representa, o autor coloca em sua fala a relação com os animais, seja no homem como bicho, seja no bicho como homem. Assim, como, por exemplo, na foto do lixão publicada no livro Terra, de Sebastião Salgado (1997), os urubus têm lugar na cena em foco. A diferença é que na narrativa não se coloca a superioridade dos bichos sobre o homem, mas sua equiparação, em uma fala afetiva, que interroga as relações humanas.

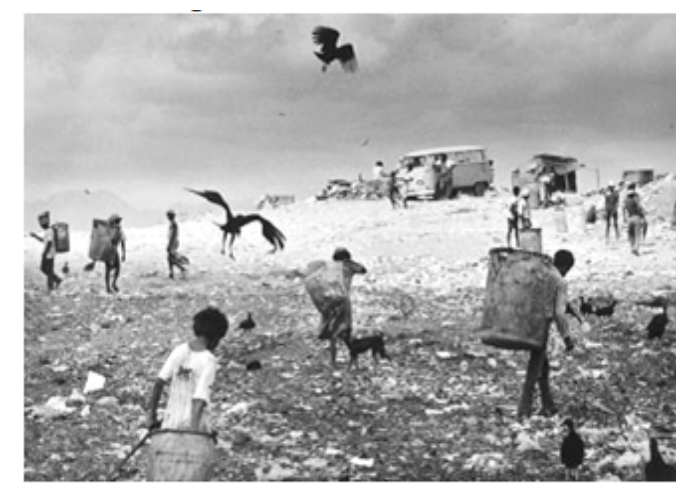

Figura 1. Lixão de Fortaleza. Fonte: Salgado (1997, p. 76-77). 
Rituais e instituições são deslocados quando se encontram metonimicamente representados no texto. Mais do que representados, eles são, na verdade, apontados alegoricamente, em sua ligação com a violência:

Tanto povo que compra o que não gasta - roupa nova, véu, grinalda. Minha filha já vestiu um vestido de noiva, até a aliança a gente encontrou aqui, num corpo. É. Vem parar muito bicho morto. Muito homem, muito criminoso. A gente já tá acostumado. Até o camburão da polícia deixa seu lixo aqui, depositado. Balas, revólver 38. A gente não tem medo, moço. A gente é só ficar calado (Freire, 2007, p. 12).

A relação entre a violência das armas e o lugar do silenciamento é também desveladora. Lugares de poder, em princípio, fora do domínio do Estado, se confundem com suas instituições, como se pode ver na referência a camburões de polícia e a balas de revólver.

Para criar tal narradora, Marcelino Freire compõe seu cenário com materiais encontrados no lixão. Tais materiais, ao serem exibidos como elementos vitais - comida, remédios, móveis, roupas -, abarcam diferentes setores da sociedade capitalista em seu afã de consumo.

Na medida em que objetos vão sendo arrolados, desmancha-se o monte de lixo literal e metaforicamente. Para compreender tal assertiva há que evocar, mais uma vez, José Carlos Rodrigues (1995), quando ressalta a analogia entre morte e lixo e, entre este e a ideia de ameaça à ordem, já tão estudada por outros antropólogos. Diz o autor:

A questão da morte tem muito a ver com a do lixo. Não tanto, ao contrário do que tenderíamos a acreditar, porque o lixo já tenha morrido, que já não sirva e a que se tente dar uma sobrevida através dessa preocupação bem contemporânea que é a reciclagem. Ele é isto também. Mas a analogia entre morte e lixo se faz muito mais forte em nosso tempo porque na cultura industrial morrer é mais ou menos ir para o lixo. Aí está certamente uma das razões de nossa angústia em torno de ambos os fenômenos. Assim, uma dupla afinidade simbólica existe em nossa cultura entre morte e lixo: quer porque o que vai para o lixo seja o que está morto, quer porque morrer corresponda a ir para o lixo (Rodrigues, 1995, p. 12).

Mais que irônico, o texto de Marcelino Freire parece inverter a visão tradicional que denuncia a vida desumana nas e das sobras do lixo da sociedade de consumo, que já não incomoda ninguém. Ao invés disso, escancara-se a permanência de um modo de sobrevivência, metáfora ele mesmo do sistema que o gerou. "Não, eles nunca vão tirar a gente deste 
lixão. Tenho fé em Deus, com ajuda de Deus, eles não vão tirar a gente deste lixo. Eles dizem que sim, que vão. Mas não acredito. Eles nunca vão conseguir tirar a gente deste paraíso" (Freire, 2007, p. 13).

A ambiguidade narrativa propõe a relação entre lixo e vida, quando o usual é a feita entre lixo e morte. Observa-se, no entanto, que, mesmo que a vida advenha do lixo, aí se encontram signos da morte, da ferida: "esparadrapo, band-aid e seringa" (Freire, 2007, p. 10). Essa ferida não é circunscrita ao domínio dos excluídos, pois é uma ferida social, expressão da obscenidade do real: "o Real em sua violência extrema como o preço a ser pago pela retirada das camadas enganadoras da realidade" (Zizek, 2003, p. 19).

Na ficção de Marcelino Freire, evidencia-se o processo escatológico, no sentido de excremento, ligado a kôr, scatós, do grego, assim como o sentido de extremo, último, éskhatos, também do grego. Nessa significação há ainda a ideia de renovação, da possibilidade de um novo tempo, o que liga escatologia e cosmogonia, propiciando o tempo cíclico que marca o mito, ou, paradoxalmente, apontando a fratura que lhe é inerente. No nível da enunciação, porém, a escrita, apropriando-se do lixo, desloca-o, fazendo da sujeira amorfa, que poderia significar afasia, ou, como quer Jurandir Freire Costa (2000), "desinvestimento cultural", tática de sobrevivência (Cury e Walty, 2003).

O lixo é a matéria, por excelência, do texto e da sociedade. E é esse lixo circulando na superfície do texto que impede o olhar dicotômico, com que geralmente a sociedade pede para ser lida: de um lado os pobres, sujos, ameaçadores; de outro, as pessoas de bem, responsáveis, honestas, respeitáveis.

Ao fazer do lixo matéria de seu texto tal qual sua narradora o utiliza como matéria de sua vida, Marcelino Freire realiza o trabalho alegórico a que se refere Benjamin (1984). Assim, o relato feito de cacos de discursos, como as vidas construídas com sobras do consumo, cumpriria a função da alegoria, apontando para o sofrimento e arrancando não a obra de arte de sua totalidade, mas a própria ordem social, "para mostrar a sua verdade fragmentada". Sua intrusão seria "caracterizada como um grande delito contra a paz e a ordem", não "no campo da normatividade artística" (Benjamin, 1984, p. 199), mas no campo da normatividade sociopolítica (Walty, 2005, p. 35). 
Ivete Lara Camargos Walty

\section{Darluz: a vida em jogo}

Esse jogo alegórico se exibe no nível da textualidade, tanto entre os textos do mesmo livro como entre textos de diferentes publicações do autor, provocando e reiterando uma ampliação do texto para a sociedade, do mundo dos excluídos para o dos não excluídos. O conto "Darluz", por exemplo, retoma "O caso da menina" (Freire, 2000), do mesmo autor, em que se coloca face a face uma mulher com uma filha nos braços e um "Senhor", a quem ela quer entregar a filha. Aí, por meio de frases curtas e também interrogativas, a fala da mãe, marcada pelos grandes nomes da mídia, como Xuxa e Angélica, e atravessada pela fina ironia do autor implícito, inverte a culpa pelo ato de descartar a filha, ampliando-a para fora dos limites da narrativa. Na rua, oferece-se ao interlocutor uma mercadoria, ironicamente, de graça, o que desvela o jogo da sociedade capitalista e suas relações assimétricas. Mais uma vez, ao ser humano associa-se o lixo, ou, mais do que isso, a criança, ao ser objeto de venda, faz-se lixo. Isso porque, no que seria a rejeição do interlocutor que não aceita comprá-la, metaforiza-se a rejeição da sociedade que a relega.

Quer?

Não entendi.

A criança.

Quer?

Hã?

A menina.

$[\ldots]$

Minha senhora...

Jogue ela no lixo.

O quê?

Faça isso. Jogue ela no lixo.

No lixo?

Num bueiro.

Bueiro?

É.

Vou chamar a polícia. A senhora é louca.

O senhor é que é louco.

$\mathrm{Eu}$ ?

Louco e filho da puta.

Tô oferecendo e o senhor não quer.

Como é que é?

Eu é que devo chamar a polícia.

22 est. lit. bras. contemp., Brasília, n. 41, p. 17-31, jan./jun. 2013 
$[\ldots]$

A senhora é louca, louca.

Socorro!

Calma!

Vá embora.

Eu não fiz nada.

Fez, sim.

$\mathrm{Eu}$ ?

Fazer isso com a pobrezinha.

(Freire, 2000, p. 91-95).

Em "Darluz", uma favelada, que pode ser caracterizada como a mesma personagem, declara a respeito dos filhos gerados por ela: "Dei José, dei Antônio, Maria dei. Daria. Dou. Quantos vierem. É só abrir os olhos. Nem bem chorou, xô. Não posso criar. É feito gato, não tem mistério. É feito cachorro de rua. Rato no esgoto" (Freire, 2007, p. 23).

$\mathrm{Na}$ fala da mulher, construída com frases curtas e reiterativas, marcadas pelo verbo dar, em sua múltipla significação, imiscuem-se várias cenas enunciativas, além da que integra a narradora e seu ouvinte. É o caso da relação da narradora com alguém que lhe aconselha providências a tomar para melhorar sua vida.

Moço, quem cria? Não é fácil pimenta no cu dos outros. Aí vem a madame, aí vem gente dizer: arranje um trabalho. Arranje você. Me dê o trabalho agora. [...] Vem você dar um jeito no mundo, repartir seu quarto.

$[\ldots]$

E tem mais. Todo mundo é solidário. Mas na hora, olha, o povo é foda. Vem aconselhar pílula, distribuir planejamento. Quero saber o que fazem com nosso sofrimento. Vai, quem diz? (Freire, 2007, p. 23).

$\mathrm{Na}$ invocação de outras vozes, instala-se uma contraposição entre o lugar de fala da narradora e daqueles que a interpelam. De um lado fome, carência de educação e saúde, sofrimento; de outro trabalho, religiosidade, templos de consumo, recursos médicos. $\mathrm{O}$ discurso da mãe afronta os discursos prontos, na medida em que expõe suas lacunas, sobretudo no que se refere ao lugar social da mãe. "Dizer que ninguém abandona ninguém, que toda mãe é mãe até o fim, tá aqui, ó. Sou mais mãe que muita mãe aí. Leva o filho para a escola e abandona. Leva o filho para o shopping e abandona. Para a puta que pariu e abandona" (Freire, 2007, p. 26). 
A dessacralização se fortalece na evocação de Maria em sua relação com São José, que expõe o lugar da mulher e sua obrigação de cuidar dos filhos sem o apoio do pai: "Veja Maria, pôs Jesus no mundo, filho do espírito santo. O pai largou. Você viu como José sumiu, se evaporou? Maria é que foi lá, no pé da cruz, se arrepender. Eu, não. Eu quero mais é distância. Você ter filho chorando, no seu pé (Freire, 2007, p. 24).

A ideia de ferida e dor que atravessa o texto leva à imagem da cicatriz, do calo provocado pelo sofrimento constante. É essa cicatriz que o conto reabre, quando do conjunto de estratégias surge a voz do autor implícito, iluminando o discurso social em seu controle não só o número de filhos dos pobres mas de sua vida.

\section{Da Paz: a paz inventada}

É essa ferida/cicatriz que se imprime no conto "Da Paz", em que um discurso raivoso, sincopado e incisivo, encena-se, na fala da mulher da favela, a mãe, que perdera o filho para a violência, e se recusa a participar das manifestações pela paz organizadas pelos moradores do asfalto:

Quem vai ressuscitar meu filho, o Joaquim? Eu é que não vou levar a foto do menino para ficar exibindo lá embaixo. Carregando na avenida minha ferida. Marchar não vou, muito menos ao lado de polícia. Toda vez que vejo a foto do Joaquim dá um nó. Uma saudade. Sabe? Uma dor na vista. Um cisco no peito. Sem fim. Uma dor (Freire, 2007, p. 31).

A contraposição entre a favela e o asfalto acentua o divórcio entre a percepção de mundos diversos, ao mesmo tempo em que dissemina a violência atribuída a lugares de exclusão e pobreza. É então que se instala a diferença da concepção de violência e paz:

Eu não sou da paz.

Não sou mesmo não. Não sou. Paz é coisa de rico. Não visto camiseta nenhuma não, senhor. Não solto pomba nenhuma não, senhor. $[\ldots]$

Se quiser vá você, diacho. Eu é que não vou. Atirar uma lágrima. A paz é organizada. Muito certinha, tadinha. A paz tem hora marcada. Vem governador participar. E prefeito. E senador. E até jogador de futebol (Freire, 2007, p. 28).

Outra vez a reiteração do "não" marca a recusa de um tipo de paz encenada nas avenidas e na mídia. Importa lembrar que o conto, escrito sob 
encomenda do Estado de S. Paulo, por ocasião dos arrastões que assustaram a cidade em 2006, não foi aceito para publicação pelo jornal. É que ele desvela relações sociais que são da ordem da abjeção, do real que ameaça a ordem instituída sobre a assimetria e a injustiça social.

Como nos contos anteriores, um enunciatário é construído no texto para ouvir essa fala dissonante, essa latomia, que troca as coisas de lugar como se trocam as palavras nas frases: "Uma dor na vista. Um cisco no peito" (Freire, 2007, p. 31). Nesse choro agressivo, revoltado e revoltante, contrapõem-se a violência das relações sociais e o que seria uma pantomima armada para as telas de TV: "A paz fica bonita na televisão" (Freire, 2007, p. 28).

As metonímias da paz - pomba, rosa, terço -, em contraponto com os gestos agressivos incorporados na oralidade da narrativa, se desfazem na voz raivosa daquela que, representando seu grupo social, põe o dedo na ferida, a sua e a da sociedade. Dessa forma, o conto, mesmo que dicotomicamente, abre os ouvidos e os olhos do leitor para o mundo em que se encontra inserido. Pessoas e coisas se (des)misturam, se deslocam, "bagunçando o coro dos contentes".

\section{Totonha: a educação pelo avesso}

Outra interlocução se encena no conto que tematiza a educação de adultos. Dessa feita a interlocutora é uma moça, mocinha, uma possível professora da zona rural. Na fala de Totonha, mais uma vez marcada pelas interrogações, grava-se a resistência às determinações de cima para baixo:

Capim sabe ler? Escrever? Já viu cachorro letrado, científico? Já viu juízo de valor? Em quê? Não quero aprender, dispenso.

Deixa pra gente que é moço. Gente que tem ainda vontade de doutorar. De falar bonito. De salvar vida de pobre. O pobre só precisa ser pobre. E mais nada precisa. Deixa eu, aqui no meu canto. $\mathrm{Na}$ boca do fogão é que fico. Tô bem. Já viu fogo ir atrás de sílaba? (Freire, 2007, p. 19).

Ironicamente toma-se como alvo o intelectual em sua vontade de dirigir os grupos oprimidos, excluídos, ou o político em seu jogo de fazer para aparecer. Outra visão de mundo marcada pela interação com a natureza rege o discurso.

Aprender com o vento, tá me entendendo? Demente como um mosquito. Na bosta ali, da cabrita. Que ninguém respeita mais a bosta do que eu. A química.Tem coisa mais bonita? A geografia do 
Ivete Lara Camargos Walty

rio mesmo seco, mesmo esculhambado? O risco da poeira? O pó da água? Hein? O que eu vou fazer com essa cartilha? Número? (Freire, 2007, p. 20).

Como as metáforas que associam elementos inusitados, como água e pó, as fronteiras do mundo estabelecido se abalam, permitindo uma percepção outra, marcada pelo fazer poético em sua concepção básica de criação.

Só para o prefeito dizer que valeu a pena o esforço? Tem esforço mais esforço que o meu esforço? Todo dia, há tanto tempo, nesse esquecimento. Acordando com o sol. Tem melhor bê-á-bá? Assoletrar se a chuva vem? Se não vem?Morrer já sei. Comer, também. De vez em quando, ir atrás de preá, caruá. Roer osso de tatu. Adivinhar quando a coceira é só uma coceira, não uma doença. Tenha santa paciência! (Freire, 2007, p. 20).

A repetição das palavras na frase, traduzindo o cotidiano na luta pela vida, assinala o teor lírico do texto e sua conformação de um mundo outro, possivelmente ignorado pelos que se tomam por sábios. Imprime-se no texto a questão identitária na discussão da importância do nome.

Será que eu preciso mesmo garranchear meu nome? Desenhar só para a mocinha aí ficar contente? Dona professora, que valia tem meu nome numa folha de papel, me diga honestamente. Coisa mais sem vida é um nome, assim, sem gente. Quem está atrás do nome não conta?No papel, sou menos ninguém do que aqui, no Vale do Jequitinhonha. Pelo menos aqui todo mundo me conhece. Grita, apelida. Vem me chamar de Totonha. Quase não mudo de roupa, quase não mudo de lugar. Sou sempre a mesma pessoa. Que voa (Freire, 2007, p. 20-21).

Na construção do conto, um eu, no aqui e no agora, toma a palavra e se assume como sujeito, dispensando, aparentemente, a chancela do saber formalizado ditado pela escola. Nas frases "Sou sempre a mesma pessoa. Que voa", instala-se o paradoxo na medida em que a permanência se dá na diferença, na capacidade de "voar". A capacidade de comunicar com os pássaros remonta à capacidade de comunicar com o mundo dos povos dados como primitivos, de que fala Todorov em seus estudos sobre os Astecas. O autor se interroga:

Seria forçar o sentido da palavra "comunicação" dizer, a partir disso, que há duas grandes formas de comunicação, uma entre os homens, e outra entre o homem e o mundo, e constatar que os índios cultivam principalmente a primeira? Estamos habituados a conceber somente a comunicação inter-humana, pois, "o mundo" 
não sendo um sujeito, o diálogo com ele é bastante assimétrico (se é que é diálogo). Mas talvez esta seja uma visão limitada, responsável, aliás, pelo sentimento de superioridade que temos nesse campo (Todorov, 1983, p. 67).

É a um tipo dessa superioridade colonizadora que remete a fala da narradora em seu papel questionador, explodindo a submissão àquele que não conhece seu mundo. "Não preciso ler, moça. A mocinha que aprenda. $\mathrm{O}$ prefeito que aprenda. $\mathrm{O}$ doutor. $\mathrm{O}$ presidente é que precisa saber ler o que assinou. Eu é que não vou baixar a minha cabeça para escrever. Ah, não vou" (Freire, 2007, p. 22, grifo nosso).

Irônico, no entanto, é que a escrita seja a ferramenta que grava a fala da analfabeta e a faz circular, o que relativiza a dicotomia entre lados opostos, tanto no que se refere à relação oralidade/escrita quanto no que se refere aos diferentes grupos sociais.

De qualquer forma, como se viu, um elemento a se repetir nos contos de Marcelino Freire é o da resistência à tentativa de controle daquele que, determinado pela própria ordem social, escapa a ela e a ela ameaça. É desse controle que fala também o conto "Comadre".

\section{Comadre: o traço enviesado}

No conto em epígrafe, antes intitulado "Balé" (Freire, 2003), lirismo e discordância se mesclam em um discurso de resistência, deslocando lugares sociais estabelecidos. Frases iniciadas pela forma verbal "disse", aparentemente sem sujeito, situam as personagens que se contrapõem: as comadres - a mãe e a possível madrinha - e o filho "rebelde".

Disse que não, não vai cortar cana, morrer, moer neste sol.

Disse que não, não vai ajudar o pai, salvar a mãe, os irmãos.

Disse que não, bateu o pé, quer ir embora aqui de Catolé (Freire, 2007, p. 14).

No discurso do narrador, contrapõem-se dois espaços - o aqui e um algures, um outro lugar possível - diferente daquele em que se prega a obediência aos pais e ao destino, à religião, seja a católica, seja a do candomblé:

Disse que não. Não acredita em promessa. Pecado é viver na devoção. Que a gente é que tá errado de ter trabalho e garantir o pão. Pão que ele come. Por mim, deixava este diabo morrer de fome. Mas 
Ivete Lara Camargos Walty

comadre tem pena, comadre diz que passa, comadre diz que ele um dia melhora (Freire, 2007, p. 15).

O poético penetra na fala da comadre, caracterizando um novo discurso, proveniente de um enunciador outro que exercita sua subjetividade por meio das estratégias textuais utilizadas pelo autor. A cada negativa da narradora, afirma-se o caráter do filho/afilhado em sua busca de outra vida:

Acredita que o negócio dele é ficar dançando?

É, mulher, dançando. Vive atrás de vento, assobiando. Diz que segue canto de passarinho, que escuta água chover embaixo da terra. Vê só, ele ali na ponta quente da pedra se equilibrando (Freire, 2007, p. 17).

A sutileza do texto indicia resistência a uma forma insidiosa e oculta de uma violência exercida na vida diária e suas imposições de modelos. Tal resistência dá-se pela poesia da escrita, em sua representação do espaço da arte e do corpo. O uso do gerúndio - dançando, assobiando, equilibrando - imprime movimento e continuidade às frases e às ações, o que indicia a substituição do discurso instituído pelo instituinte.

\section{Conclusão}

Entre o campo e a cidade, transita a personagem de Marcelino Freire, que tem escrito como quem escuta o outro, em um exercício de alteridade, como se pôde observar na fala de mulheres ("Muribeca", "Comadre", "Darluz", “Da Paz", “Totonha"), em que vozes sociais expõem-se em tensão com a voz autoral, fruto das estratégias utilizadas na composição de uma escrita explicitamente interlocutória que inclui o leitor.

Não por acaso, os contos antes publicados em outros livros ou em blogs aparecem juntos em um livro intitulado Sertânias, publicado pela editora Dulcineia Catadora, que assim se define em seu blog:

Todas as iniciativas do Dulcinéia Catadora têm sempre o compromisso com a distribuição do conhecimento e da renda, a divulgação de autores latino-americanos, a valorização e a promoção da autoestima dos catadores, e o estímulo à criatividade.

Convidado para a $27^{\mathrm{a}}$ Bienal de São Paulo, o Eloísa Cartonera apresentou-se no pavilhão como um atelier em funcionamento permanente. Ao grupo argentino, existente em Buenos Aires desde 2003, somou-se a participação de catadores, filhos de catadores 
e artistas brasileiros. Daí se originou seu projeto-irmão, Dulcinéia Catadora, que funciona de forma independente, no Brasil, com a artista plástica Lúcia Rosa, as pinturas espontâneas de Peterson, Tatiana, Andréia, e conta com a colaboração de Carlos Pessoa Rosa, Douglas Diegues e Rodrigo Ciríaco na seleção de textos e promoção de eventos (Projeto, 2007).

Nessa editora, os livros, de autores iniciantes ou famosos, são feitos com papel reciclável e capas artesanais, elaboradas, uma a uma, por participantes de oficinas geridas pelo projeto. Vê-se, pois, um bom exemplo de uma rede que, formando-se com os restos sociais, literais ou metafóricos, penetra em recintos consagrados como a Bienal de São Paulo, associandoos a lugares "marginais", como aqueles que acolhem as manifestações culturais em geral desprestigiadas.

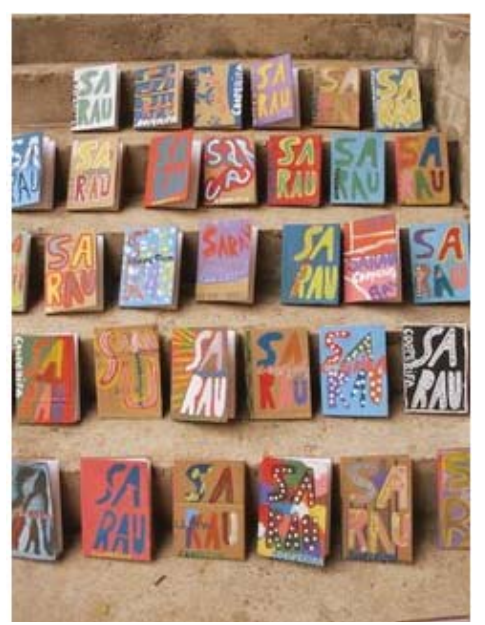

Fonte: Colecionar (2007).

Mais do que isso, abre-se a história da literatura brasileira para acolher duplamente projetos de rua, sobre a rua e da rua. Nessa via, insere-se também o tratamento dado pela literatura ao pobre. Afinal, "a situação da literatura diante da pobreza" continua sendo "uma questão estética radical" (cf. Schwarz, 1983, p. 8). 


\section{Referências}

BENJAMIN, Walter (1984). Origem do drama barroco alemão. Trad. Sérgio Paulo Rouanet. São Paulo: Brasiliense.

PROJETO Dulcineia catadora apresenta. (2007). Colecionador de pedras. Blog de Sergio Vaz. 11 fev. Disponível em: <http:/ / colecionadordepedras.blogspot.com. br/2007/02/ projeto-dulcinia-catadora-apresenta.html>. Acesso em: 3 mar. 2009. COSTA, Jurandir Freire (2000). Playdoier pelos irmãos. In: KEHL, Maria Rita (org.). Função fraterna. Rio de Janeiro: Relume Dumará.

CURY, Maria Zilda; WALTY, Ivete (2003). In memoriam: escrita e lixo. Cerrados, Brasília, n. 17, p. 55-60. Literatura e globalização.

FREIRE, Marcelino (2000). Angu de sangue. São Paulo: Ateliê. Balé/ralé. São Paulo: Ateliê.

(2007). Sertânias. São Paulo: Dulcineia Catadora.

RODRIGUES, José Carlos (1995). Higiene e ilusão: o lixo como invento social. Rio de Janeiro: Nau.

SALGADO, Sebastião (1997). Terra. São Paulo: Companhia das Letras.

TODOROV, Tzevtan (1983). A conquista da América: a questão do outro. Tradução de Beatriz Perrone-Moisés. São Paulo: Martins Fontes.

ZIZEK, Slavoj (2003). Paixões do real, paixões do semblante. In: Bem-vindo ao deserto do real: cinco ensaios sobre o 11 de setembro e datas relacionadas. Tradução de Paulo Cezar Castanheira. São Paulo: Boitempo.

Recebido em maio de 2012.

Aprovado em outubro de 2012.

\section{resumolabstract}

\section{Cinco mulheres: vozes em ricochete}

Ivete Lara Camargos Walty

Entre o campo e a cidade, transita a personagem de Marcelino Freire, que tem escrito como quem escuta o outro, em um exercício de alteridade. Tomando como ponto de partida o jogo de enunciação e encenação que move os textos, objetivase acompanhar o trânsito de cinco mulheres pobres, "Muribeca", "Comadre", "Darluz", "Da Paz" e "Totonha", para evidenciar como vozes sociais expõem-se em tensão com a voz autoral, fruto das estratégias utilizadas na composição de uma escrita explicitamente interlocutória que inclui o leitor.

Palavras-chave: enunciação, encenação, pobreza, alteridade.

\section{Five women: rebounding voices}

Ivete Lara Camargos Walty 
Marcelino Freire, whose character moves between the countryside and the city, has been writing as one who hears the others, exercising alterity. Taking as a starting point the texts' enunciation and inscenation dynamics, this work aims to follow the path of five poor women, "Muribeca", "Comadre", "Darluz", "Da Paz" and "Totonha", pointing to the tension exposed between the social voices presented and the author's voice. The latter comes as the result of strategies used in the composing of an explicitly interlocutory writing, which includes the reader.

Keywords: enunciation, encenation, poverty, alterity, 